SURGICAL REPAIR AND RECONSTRUCTION IN RHEUMATOID DISEASE 


\section{SURGICAL REPAIR AND RECONSTRUCTION IN RHEUMATOID DISEASE}

\section{Alexander Benjamin MB, BS, FRCS}

Orthopaedic Surgeon to Peace Memorial Hospital, Watford, West Herts Hospital, Hemel Hempstead

Honorary Lecturer, Postgraduate Institute of Orthopaedics

and

Basil Helal MB, BS, MCh (Orth), FRCS

Orthopaedic Surgeon to The London Hospital,

Chase Farm Hospital, Enfield,

Highlands Hospital, Winchmore Hill

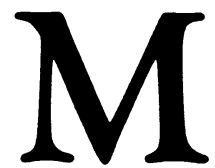


(C) Alexander Benjamin and Basil Helal 1980

Softcover reprint of the hardcover 1st edition 1980 978-0-333-24683-2

All rights reserved. No part of this publication may be reproduced or transmitted, in any form or by any means, without permission

First published 1980 by

THE MACMILLAN PRESS LTD

London and Basingstoke

Associated companies in Delhi Dublin

Hong Kong Johannesburg Lagos Melbourne

New York Singapore and Tokyo

\section{British Library Cataloguing in Publication Data}

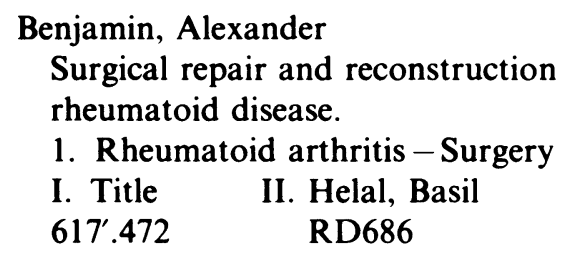

ISBN 978-1-349-04137-4 ISBN 978-1-349-04135-0 (eBook)

DOI 10.1007/978-1-349-04135-0

This book is sold subject to the standard conditions of the Net Book Agreement 


\section{CONTENTS}

Foreword 1 by Barbara M. Ansell

Foreword 2 by Kauko Vainio

vii

Preface

viii

1 General considerations

2 The link with medical management

3 Perioperative care

4 Synovectomy

5 Osteotomy

6 Arthroplasty

7 Arthrodesis

8 The spine

9 The shoulder

10 The elbow

11 The wrist

12 The hand

13 The hip

14 The knee

Author index 


\section{FOREWORD 1}

Barbara M. Ansell, Clinical Research Centre, Division of Rheumatology Northwick Park.

Despite the cause, or causes, of rheumatoid disease still evading elucidation, the overall care of patients with this serious and potentially crippling illness has improved remarkably in the last two to three decades. This is partly due to the increased number of drugs available and a better understanding of how to use them, but particularly to the close collaboration of orthopaedic surgeons and physicians in attempting to minimise pain and disability not only through the appropriate use of drugs, but by the critical employment of recognised surgical techniques and the development of new ones.

Alec Benjamin and Basil Helal, who have extensive experience, open with general remarks on rheumatoid disease and the links with medical management, before discussing pre-operative assessment of patients and the main types of operative techniques that are available; chapters relating to specific joints or sites follow. This is a thoughtful and thought-provoking book which demonstrates critically the indications and outcome of the operations that are available. Perhaps even more important, it offers advice on the selection of the most suitable procedure for any given patient at a certain stage in the disease. At the present state of our knowledge the guidelines that these authors have tried to establish will be of great help to rheumatologists and orthopaedic surgeons alike. The development of improved techniques and the reappraisal of old ones will necessitate re-definition of indications for management. However, for many years to come this book will aid any team aiming to improve function and relieve pain through the surgical treatment of rheumatoid arthritis. 


\title{
FOREWORD 2
}

\author{
Kauko Vainio, Heinola, Finland
}

Although surgery has blossomed over the past century, rheumatoid arthritis was until relatively recent times taboo for the surgeon with the exception of a few brave pioneers. The fear was that operation might cause an exacerbation of the disease and a more important factor was that co-operation between surgeons and rheumatologists was, at best, very poor. During the past 25 years the climate of opinion has changed completely. Surgery is now an inseparable part of the overall treatment of rheumatoid disease and there is a close liaison between surgeon and rheumatologist.

The authors point out the fact that the surgeon and rheumatologist must be able to speak the same language. Thus, they start the book with a chapter on the pathology and medical management of the disease, not forgetting the important psychological factors. The chapter includes the latest knowledge on these subjects and will be of value to every surgeon.

Before discussing treatment of the individual joints the authors deal in general with the basic operations in rheumatoid arthritis, viz. synovectomy, osteotomy, arthroplasty and arthrodesis. They warn against over-enthusiasm in the use of prostheses and lay stress on the possible complications. They use osteotomies much more than many surgeons. This is an easy and inexpensive operation and if the results in suitable cases are comparable with those using expensive prostheses then the procedure should be used more. Multicentral research is necessary to elucidate this point.

In the chapters concerning interventions in different joints the authors present several new methods. These, as well as the old ones, are described sufficiently accurately to make it possible for every specialist to follow the techniques described which are clarified with numerous illustrations.

As an elderly surgeon who has spent his working life closely involved in the development of surgery of rheumatoid arthritis I welcome this new book with great pleasure. 


\section{PREFACE}

This book draws largely on personal experience and is a practical guide to what we consider to be the best practice in the management of this difficult disease. We have been didactic in our presentation but are aware that other methods can have similar results. On controversial issues we have tried to present a reasoned synthesis of opinion, and whereas our own views occasionally conflict, we have found a degree of agreement perhaps unusual between two orthopaedic surgeons.

The seeds of this book were sown in 1970 at a meeting held to found the Rheumatoid Arthritis Surgical Society. The authors formed half of the quartet which founded the Society. Much of what we have learned has been gleaned at our meetings from fellow members, who, between them, represent a global opinion on this subject, for they include prominent rheumatological surgeons from Austria, Canada, Finland, Germany, Norway, Poland, Spain, Sweden, Switzerland and the United States of America.

Two of the members from Britain, George Arden and Barbara Ansell, have combined their unique experience into a book, The Surgical Management of Juvenile Chronic Polyarthritis, published by Academic Press Ltd. We have therefore deliberately avoided touching upon this topic and trust that the two books will complement each other.

We appreciate the tolerance of our wives, Stella and Bobbie, and of our children, and apologise for the many 'lost' evenings and weekends. We also greatly appreciate the remarkable patience of our secretaries, Bobbie Benjamin and Jenny Parke.

We are most grateful to the many surgeons and physicians and others who have kindly provided us with photographic material. They are individually acknowledged and we beg forgiveness of anyone we have omitted to mention.

We are indebted to John Collins of the Royal National Orthopaedic Hospital, to Martin Moor of Enfield District Hospital, to Ray Ruddick of the London Hospital and to Sidney Berlanney for photography, and to John Waterhouse for the art work.

As script readers we were most fortunate in having John Kirkup, Michael Salz and Michael Sullivan. Their wisdom and advice has been valuable beyond measure.

The co-operation of Macmillan Press Ltd has been exemplary and we are indebted to them for the smooth and rapid passage to publication.

We are honoured that Kauko Vainio and Barbara Ansell, who are, respectively, two of the most outstanding contributors to the surgical and medical aspects of rheumatology, have compiled the forewords.

Finally we take this opportunity to thank our teachers, many of whom are from our medical school, The London Hospital.

A. B.

B. $\mathrm{H}$. 